\title{
Analisis Kualitas Layanan pada Bagian Rawat Inap Rumah Sakit di Bandung
}

\author{
Ina Ratnamiasih \\ Fakultas Ekonomi Universitas Pasundan, Bandung \\ J1. Tamansari No. 6-8 Bandung 40116 \\ E-Mail: inaratnamiasih@gmail.com \\ Rajesri Govindaraju \\ E-Mail: Rajesri_g@gmail.ti.itb.ac.id \\ Budhi Prihartono \\ E-Mail:budhipri@widyatama.ac.id
}

Iman Sudirman

\begin{abstract}
Hospital has an important role for the growth of a country. Poor of hospital quality care cause public health problems are not immediately addressed. This research aim to have an explanation about inhouse quality of hospital services. However, measurements taken by the patient's perception produce a picture of the quality of care in hospitals. This research followed an established case study method. A range of general hospital were contacted for this research. The hospitals vary in regards to ownership, as a private and public hospital. Only 6 of 19 hospitals showed interest and willingness to spare part of their time to be observed. The results showed that the quality of hospital services is relatively good. However, there are significant complaints about the lack of time provided by doctors, the hospitals are not continuously provide information about the disease by the patient, including the information of possible complications, and lack of hospital policy to train and give an explanation about disease and pain handling.
\end{abstract}

Keywords: quality of hospital services, doctors, nurses.

\begin{abstract}
ABSTRAK
Rumah sakit memegang peranan penting bagi pertumbuhan suatu negara. Kualitas layanan rumah sakit yang buruk menyebabkan permasalahan kesehatan masyarakat tidak terselesaikan. Penelitian ini dilakukan untuk mendapatkan gambaran mengenai kualitas layanan bagian rawat inap rumah sakit di Bandung. Bagaimanapun, pengukuran yang dilakukan dengan menggunakan persepsi pasien dapat menghasilkan gambaran mengenai kualitas layanan rumah sakit. Penelitian ini menggunakan metode studi kasus. Rumah sakit umum telah dihubungi untuk menjadi objek penelitian ini. Rumah sakit beragam dalam hal kepemilikannya, yaitu sebagai rumah sakit milik swasta dan milik pemerintah. Hanya 6 dari 19 rumah sakit yang tertarik dan bersedia meluangkan waktu untuk diteliti. Hasil penelitian menunjukkan bahwa kualitas layanan rumah sakit relatif sudah baik. Namun, terdapat keluhan yang cukup signifikan mengenai kurangnya waktu yang disediakan oleh dokter, rumah sakit tidak secara kontinyu memberikan informasi mengenai penyakit pasien, termasuk informasi mengenai kemungkinan komplikasinya, dan kurangnya kebijakan rumah sakit dalam melatih dan menjelaskan tentang cara menangani rasa sakit
\end{abstract}

Kata Kunci: kualitas layanan rumah sakit, dokter, perawat. 


\section{PENDAHULUAN}

Penelitian mengenai kualitas layanan telah banyak dilakukan oleh para peneliti sebelumnya. Sebagian penelitian dilakukan untuk menentukan faktor-faktor pembentuk kualitas layanan. Sebagian penelitian lainnya dilakukan untuk menentukan faktorfaktor yang mempengaruhi kualitas layanan. Secara umum, rumah sakit sebagai organisasi jasa memiliki karakteristik yaitu kinerja yang dihasilkannya tidak berwujud dan cepat hilang, produk yang diberikan lebih dapat dirasakan daripada dimiliki, serta pelanggan dapat lebih berpartisipasi aktif dalam proses memproduksi dan mengkonsumsi jasa (Kotler dan Keller, 2006). Oleh karena itu, kinerja rumah sakit lebih sulit diukur, terutama dalam hal kualitas layanan (Ko et al., 2010).

Kualitas layanan rumah sakit di Indonesia masih dirasa kurang memuaskan (Supratman dan Prasetyo, 2010). Permasalahan kualitas tersebut terutama dirasakan oleh pasien yang berasal dari golongan ekonomi lemah. Pasien yang berasal dari golongan ekonomi lemah adalah pasien yang tidak mampu membayar biaya pengobatan yang dibutuhkannya. Bagi pasien yang tidak mampu, beberapa masalah yang dikeluhkan di antaranya, waktu tunggu pasien untuk dilayani seringkali sangat terlambat dan tidak sesuai dengan jadwal praktek yang sudah ditetapkan (Jonirasmanto, 2009; Supratman dan Prasetyo, 2010) dan beberapa pasien yang diwawancarai pada studi pendahuluan menyatakan bahwa informasi yang diberikan kepada pasien masih kurang, dalam upaya mendidik pasien untuk mengobati dan memelihara kesehatannya sendiri.

Terdapat perbedaan antara perawatan yang diberikan oleh rumah sakit pada pasien rawat inap dan rawat jalan. Mengukur kualitas layanan pada unit rawat jalan lebih sederhana daripada mengukur kualitas layanan pada unit rawat inap. Hal ini disebabkan tuntutan pasien rawat jalan lebih sederhana daripada tuntutan pasien rawat inap. Oleh karena itu keluhan-keluhan mengenai kualitas layanan lebih banyak didengar dari pasien rawat inap daripada pasien rawat jalan. Pasien rawat inap memerlukan waktu perawatan, keterlibatan dokter dan perawat, serta penggunaan fasilitas rumah sakit yang lebih banyak, sehingga kualitas layanan dirasakan lebih penting. Hal ini lah yang mendorong penelitian ini difokuskan pada kualitas layanan menurut persepsi pasien rawat inap.
Dokter merupakan elemen rumah sakit yang paling besar peranannya. Sebuah rumah sakit yang banyak pasiennya, biasanya identik dengan dokter yang baik dan infrastruktur yang lengkap. Tidak heran, karena pasien datang ke rumah sakit untuk berobat. Pada bagian rawat inap, elemen kedua yang penting adalah perawat. Perhatian dan keahlian perawat sangat dibutuhkan selama pasien tinggal di rumah sakit. Berdasarkan pertimbangan tersebut, maka penelitian mengenai kualitas layanan rumah sakit ini difokuskan pada pelayanan yang berhubungan langsung dengan perawatan pasien. Dokter dan perawat sebagai elemen utama dalam perawatan pasien, perlu dilihat kontribusinya pada kualitas layanan rumah sakit.

Faktor-faktor pembentuk kualitas layanan rumah sakit telah banyak diteliti, namun pada rumah sakit di Bandung akan diidentifikasi berdasarkan persepsi pasien bagian rawat inap. Kualitas layanan merupakan sesuatu yang bersifat perseptif sehingga pengukuran pada pasien secara langsung diharapkan menghasilkan informasi yang lebih akurat. Secara umum diharapkan penelitian ini mampu memberikan gambaran mengenai kualitas layanan pada bagian rawat inap rumah sakit di Bandung dan menjadi referensi bagi para pengambil keputusan dalam menentukan kebijakan umum pelayanan rumah sakit.

Kualitas sulit diukur pada organisasi seperti rumah sakit karena sebagai organisasi yang aktivitasnya bersifat jasa, rumah sakit memiliki keunikan. Beberapa keunikan tersebut adalah: karyawannya sebagian merupakan para profesional, sebagian besar jasa yang diberikan tidak berwujud, adanya keterlibatan yang tinggi dari pasien dalam proses penyampaian jasa, dan adanya kesenjangan informasi antara informasi yang dimiliki oleh pasien dan informasi yang dimiliki dokter dan perawat. Hal inilah yang menyebabkan secara konseptual sulit mengukur kualitas layanan (Karassavidou et al., 2009). Parasuraman et al. (1994) mendefinisikan persepsi kualitas sebagai kesenjangan antara harapan konsumen dan persepsi konsumen mengenai pelayanan yang diterimanya. Andaleeb (2000) mengartikan kualitas layanan sebagai sejauhmana rumah sakit dapat memberikan pelayanan yang prima terkait dengan kebutuhan perawatan pasien. Pendapat lain mengatakan persepsi kualitas merupakan sikap yang dihasilkan dari membandingkan antara harapan dengan persepsi mengenai kinerja yang dirasakan (Saurina dan Coenders, 2002; Nadiri dan Tumer, 
2009; Suh dan Pedersen, 2010). Menurut Choi (2006), kualitas layanan merupakan kesan relatif mengenai tingkat inferioritas atau superioritas dari organisasi dan karyawannya. Penelitian Mukherjee dan Malhotra (2006) menunjukkan bahwa untuk menilai kualitas layanan, paling efektif dilakukan melalui sejauhmana pelayanan dari karyawan yang berhubungan langsung dengan konsumen. Raja et al. (2007) menyatakan bahwa, kualitas layanan adalah nilai tertinggi yang diberikan dan seharusnya terlihat dari bagaimana pelayanan kesehatan diberikan pada pasien. Pada penelitian ini definisi kualitas layanan yaitu sejauhmana rumah sakit dapat memberikan pelayanan yang prima terkait dengan kebutuhan perawatan pasien.

Penelitian mengenai kualitas layanan, secara umum dapat dikelompokan menjadi penelitian mengenai faktor-faktor pembentuk dan faktor-faktor yang mempengaruhi kualitas layanan. Penelitian mengenai faktor pembentuk kualitas layanan, biasanya dilakukan dengan memandang kualitas layanan sebagai sebuah sistem. Hal ini banyak dilakukan pada penelitian mengenai sistem manajemen kualitas (Pachioni dan Champagne, 2008; Manjunath et al., 2007; Theodorakioglou dan Tsiotras, 2000). Penelitian mengenai faktor pembentuk kualitas layanan selama ini sering diukur dengan menggunakan dimensi Servqual dari Parasuraman et al. (1994), namun beberapa penelitian lainnya menggunakan dimensi yang secara operasional disesuaikan dengan kondisi rumah sakit. Dimensi-dimensi yang digunakan sebagai pembentuk kualitas layanan tersebut dapat dilihat pada Tabel 1.

Berdasarkan Tabel 1.dapatdilihat bahwa sebagian besar penelitian emngenai kualitas layanan rumah sakit mengadopsi dimensi Servqual dari Parasuraman et al. (1994). Beberapa peneliti menyesuaikan dengan kondisi rumah sakit seperti Duggirala et al. (2008) dan Karassavidou et al. (2009), yang mengukur gap kualitas serta menentukan dimensi yang paling penting bagi kualitas layanan. Berdasarkan hasil penelitian mereka dapat diketahui, bahwa menurut pasien, dimensi personal quality dan human aspect dianggap paling penting bagi kualitas layanan. Hubungan dokter, perawat, dan pasien merupakan bagian yang sangat penting sehingga rumah sakit perlu lebih memperhatikan manajemen sumber daya manusia agar kualitas layanan menjadi semakin baik. Hal ini sesuai dengan hasil penelitian Chilgren (2008) yang menyatakan bahwa kualitas layanan yang diharapkan oleh pasien berhubungan langsung dengan sumber daya manusia, yaitu kecepatan waktu pelayanan, sikap dan perilaku karyawan (dokter dan karyawan lainnya), serta kejelasan informasi yang diberikan.

Salah satu penelitian yang dilakukan di Indonesia yaitu membandingkan persepsi kualitas layanan menurut petugas dengan pasien pada Balai Pengobatan Puskesmas di Indramayu yang dilakukan oleh Yusup (2007). Hasil penelitiannya menunjukkan bahwa persepsi kualitas layanan menurut petugas lebih tinggi daripada menurut pasien. Dimensi kualitas layanan yang sudah baik menurut petugas adalah reliability, assurance, dan tangible, sedangkan dimensi kualitas layanan yang perlu ditingkatkan adalah responsiveness dan empathy. Berdasarkan persepsi pasien menunjukkan hasil yang berbeda, dimensi yang dianggap sudah memuaskan adalah responsiveness, assurance, dan tangible, sedangkan dimensi yang memerlukan perbaikan adalah reliability dan empathy. Terlihat bahwa penelitian yang mengukur kualitas layanan menurut persepsi pasien penting untuk diperhatikan.

Penelitian lain dilakukan oleh Andaleeb (2000) membandingkan antara kualitas layanan rumah sakit milik pemerintah dengan rumah sakit milik swasta. Hasil penelitiannya menunjukkan bahwa rumah sakit swasta lebih baik dalam hal responsiveness, discipline, dan communication. Penelitian yang dilakukan oleh Eleid (2005) untuk mencari gap antara standar akreditasi yang dimiliki oleh rumah sakit dengan realisasi kinerja rumah sakit. Sedangkan penelitian yang dilakukan oleh Raja et al. (2007) membandingkan antara standar kualitas menggunakan Malcolm Baldrige National Quality Award, European Foundation for Quality Management, dan Kanji Business Excellence Model dengan kenyataan kualitas rumah sakit.

Berdasarkan uraian tersebut, maka secara umum permasalahan yang dapat dirumuskan dalam penelitian ini adalah sejauhmana kualitas layanan rumah sakit di Bandung, dengan beberapa pertanyaan berikut (a) bagaimana kelengkapan infrastruktur yang disediakan oleh rumah sakit, (b) bagaimana layanan dari dokter dan perawat secara personal, (c) seberapa lengkap proses perawatan klinis yang diberikan, (d) seberapa besar perhatian terhadap jaminan keamanan pasien, dan (e) seberapa mudah prosedur masuk di rumah sakit. 
Tabel 1. Dimensi Kualitas Layanan Rumah Sakit

\begin{tabular}{ll}
\hline \multicolumn{1}{c}{ Nama Peneliti, Tahun } & \multicolumn{1}{c}{ Dimensi-Dimensi Kualitas Layanan } \\
\hline Jabnoun dan Rasasi, 2005; Eleid, 2005; Zarei et al., 2012. & Reliability, responsiveness, assurance, empathy, tangibles. \\
Andaleeb, 2000. & $\begin{array}{l}\text { Responsiveness, assurance, communication, discipline, income, price } \\
\text { (baksheesh), education. }\end{array}$ \\
Duggirala et al., 2008. & $\begin{array}{l}\text { Infrastructure, process of clinical care, administrative procedures, safety } \\
\text { indicators, personnel quality, overall experience of clinical care, social } \\
\text { responsibility. }\end{array}$ \\
Karassavidou et al., 2009. & $\begin{array}{l}\text { Human aspect factor, access, physical environment and infrastructure. } \\
\text { Chilgren, 2008. }\end{array}$ \\
Raja et al., 2007. & $\begin{array}{l}\text { Good patient care, responsiveness, good doctor, good reputation. } \\
\text { Leadership, process management, people management, measurement } \\
\text { of resourcestomer satisfaction. }\end{array}$ \\
Keogh KBE, 2013. & $\begin{array}{l}\text { Patient experience, safety, workforce, clinical and operational } \\
\text { effectiveness, governance and leadership. }\end{array}$ \\
\hline
\end{tabular}

\section{METODE}

Penelitian ini bersifat eksploratori karena belum ditemukan literatur di Indonesia mengenai pengukuran kualitas layanan khusus pada bagian rawat inap di Bandung. Penelitian ini menggunakan pendekatan kualitatif agar didapatkan pemahaman yang jelas mengenai faktor-faktor yang membentuk kualitas layanan rumah sakit. Penelitian ini pun lebih difokuskan pada permasalahan yang saat ini sedang berkembang. Pada saat melakukan penelitian, peneliti tidak dapat mengendalikan perilaku objek penelitian. Berdasarkan alasan-alasan tersebut maka penelitian ini tergolong pada jenis penelitian studi kasus (Yin, 1994). Penelitian ini merujuk pada metode studi kasus yang merujuk pada Yin (1994) dimana pada tahap pertama dilakukan penentuan objek penelitian dan penyusunan protokol wawancara. Seluruh rumah sakit umum yang ada di Bandung menjadi populasi. Rumah sakit yang menjadi objek penelitian adalah yang bertipe A, B, C, atau rumah sakit umum yang belum terakreditasi. Karakteristik rumah sakit tipe D dan E tidak memenuhi kriteria populasi sehingga seluruh populasi adalah 19 rumah sakit pada kelas VIP, 1, 2, dan 3. Sampai dengan penelitian ini selesai, hanya 6 rumah sakit yang bersedia untuk diteliti yang terdiri dari 3 rumah sakit umum milik pemerintah, dan 3 rumah sakit umum milik swasta.

Pada penelitian ini data primer diperoleh melalui observasi, penyebaran kuesioner dan melakukan wawancara. Data sekunder diperoleh melalui website, berupa jurnal dan company profile. Kuesioner diberikan pada pasien yang sudah mau pulang, dan diisi oleh penunggu pasien pada setiap kelas rumah sakit. Statistik deskriptif dengan program SPSS digunakan untuk menganalisis kuesioner. Wawancara tatap muka dilakukan dengan bentuk semi terstruktur dan menggunakan pertanyaan terbuka agar peneliti dapat memperjelas pertanyaan, mengklarifikasi kebingungan, dan mendapatkan jawaban yang cukup dan dapat dipahami (Sekaran, 2000). Wawancara dilakukan pada pasien kelas 3 dan pasien Jamkesmas. Proses wawancara direkam melalui tape recorder dengan waktu masing-masing selama setengah jam.

Berdasarkan penelitian Eleid dan Raja et al. diketahui bahwa manajemen sumber daya manusia memegang peranan penting bagi kualitas layanan rumah sakit. Walaupun rumah sakit merupakan organisasi seperti layaknya organisasi lainnya, namun seperti telah dijelaskan diatas, karakteristik yang unik dari rumah sakit, membuat para peneliti membuat pengukuran yang sedikit berbeda. Pada penelitian ini dimensi kualitas layanan yang digunakan dapat dilihat seperti pada Tabel 2.

Dimensi kualitas layanan rumah sakit dalam penelitian ini hanya dibatasi pada dimensi yang berhubungan langsung dengan pelayanan yang dirasakan secara personal oleh pasien dan langsung berhubungan dengan proses perawatan/pengobatan yang diberikan kepada pasien oleh dokter dan perawat. 
Tabel 2. Dimensi Kualitas layanan

\begin{tabular}{|c|c|c|c|c|}
\hline \multicolumn{2}{|r|}{ Dimensi Awal } & \multicolumn{2}{|c|}{ Dimensi yang Serupa } & \multirow{2}{*}{ Dimensi Penelitian Ini } \\
\hline Nama Dimensi & Nama Peneliti, Tahun & Nama Dimensi & Nama Peneliti, Tahun & \\
\hline Reliability & $\begin{array}{l}\text { Parasuraman et al., 1994; } \\
\text { Jabnoun dan Rasasi, 2005; } \\
\text { Eleid, 2005; Zarei et al., } 2012 .\end{array}$ & $\begin{array}{l}\text { Proses perawatan, } \\
\text { Prosedur administratif } \\
\text { Ketepatan perawatan } \\
\text { Clinical and operational } \\
\text { effectiveness }\end{array}$ & $\begin{array}{l}\text { Duggirala, 2008; } \\
\text { Raja et al., } 2007 . \\
\text { Chilgren, } 2008 . \\
\text { Keogh KBE, } 2013 .\end{array}$ & Proses perawatan \\
\hline Responsive-ness & $\begin{array}{l}\text { Parasuraman et al., 1994; } \\
\text { Jabnoun dan Rasasi, 2005; } \\
\text { Eleid, 2005; Zarei et al., } 2012 .\end{array}$ & $\begin{array}{l}\text { Komunikasi } \\
\text { Human aspect factors } \\
\text { Layanan personal } \\
\text { Petient experience }\end{array}$ & $\begin{array}{l}\text { Andaleeb, } 2000 . \\
\text { Karassavidou et al., } 2009 . \\
\text { Duggirala, } 2008 . \\
\text { Keogh KBE, } 2013 .\end{array}$ & Layanan personal \\
\hline Assurance & $\begin{array}{l}\text { Parasuraman et al., 1994; } \\
\text { Jabnoun dan Rasasi, 2005; } \\
\text { Eleid, 2005; Zarei et al., } 2012 .\end{array}$ & $\begin{array}{l}\text { Disiplin } \\
\text { Safety } \\
\text { Jaminan keamanan }\end{array}$ & $\begin{array}{l}\text { Andaleeb, } 2000 . \\
\text { Keogh KBE, } 2013 . \\
\text { Duggirala, } 2008 .\end{array}$ & Jaminan keamanan \\
\hline Empathy & $\begin{array}{l}\text { Parasuraman et al., 1994; } \\
\text { Jabnoun dan Rasasi, 2005; } \\
\text { Eleid, 2005; Zarei et al., } 2012 .\end{array}$ & $\begin{array}{l}\text { Seluruh pengalaman } \\
\text { dalam perawatan, } \\
\text { Tanggung jawab sosial }\end{array}$ & Duggirala, 2008. & $\begin{array}{l}\text { Seluruh pengalaman } \\
\text { dalam perawatan }\end{array}$ \\
\hline Tangible & $\begin{array}{l}\text { Parasuraman et al., 1994; } \\
\text { Jabnoun dan Rasasi, 2005; } \\
\text { Eleid, 2005; Zarei et al., } 2012 .\end{array}$ & $\begin{array}{l}\text { Harga } \\
\text { Akses, lingkungan fisik, } \\
\text { infrastruktur } \\
\text { Infrastruktur }\end{array}$ & $\begin{array}{l}\text { Andaleeb, } 2000 . \\
\text { Karassavidou et al., } 2009 . \\
\text { Duggirala, } 2008 .\end{array}$ & infrastruktur \\
\hline Leadership & Raja et al., 2007. & $\begin{array}{l}\text { Governance } \\
\text { and leadership }\end{array}$ & Keogh KBE, 2013. & \\
\hline $\begin{array}{l}\text { People } \\
\text { management }\end{array}$ & Raja et al., 2007. & Workforce & Keogh KBE, 2013. & \\
\hline $\begin{array}{l}\text { Measurement } \\
\text { of resources }\end{array}$ & Raja et al., 2007. & & & \\
\hline $\begin{array}{l}\text { Customer } \\
\text { satisfaction }\end{array}$ & Raja et al., 2007. & & & \\
\hline Education & Andaleeb, 2000. & & & \\
\hline
\end{tabular}

\section{HASIL}

Data mengenai kualitas layanan yang diperoleh melalui wawancara berasal dari dua orang responden yang terdiri dari, yaitu:

Y1 (responden yang mendapatkan pelayanan rawat inap pada kelas 3 dengan menggunakan kartu Jamkesmas. Pasien adalah seorang ibu dengan usia 35 tahun, yang dirawat selama 2 minggu karena melahirkan).

H1 (responden adalah orang tua dari seorang pasien yang mendapatkan pelayanan rawat inap pada kelas 3 namun sebagai pasien umum. Pasien berusia 2 bulan, yang dirawat selama 1 bulan karena menderita penyakit hydrocephalus).

\section{Infrastruktur}

Dimensi ini mengukur tingkat kemudahan mendapatkan obat di Apotik yang ada di rumah sakit dan tingkat kemudahan mendapatkan darah di bank darah milik rumah sakit. Berdasarkan wawancara dengan petugas apotek, alur pelayanan resep obat untuk pasien umum berbeda dengan alur pelayanan untuk pasien Jamkesmas. Alur pelayanan resep obat untuk pasien umum dimulai ketika dokter bersamasama dengan perawat melakukan kunjungan, selanjutnya dokter menuliskan terapi di status pasien. Perawat menuliskan kembali pada formulir permohonan obat dan membawanya ke depo. Di depo, petugas segera mengkaji serta menyiapkan sesuai permintaan dan diserahkan kembali pada perawat. 
Setelah obat tersedia, perawat memberikan kepada pasien. Formulir permintaan obat yang diserahkan oleh perawat selanjutnya diarsipkan oleh petugas depo untuk kemudian akan diperiksa kembali oleh Apoteker.

Berdasarkan penjelasan tersebut dapat diketahui bahwa pasien umum tidak perlu membeli obat sendiri. Namun, obat-obatan bagi pasien kelas 3, diperoleh dengan menggunakan resep yang harus dibeli sendiri ke Apotek. Resep obat diperoleh dari dokter pada saat dokter melakukan kunjungan. Resep obat kemudian harus dibeli sendiri oleh penunggu pasien. Pada rumah sakit yang besar, obat-obatan bagi pasien yang menggunakan Jamkesmas harus dibeli pada apotek khusus yang berbeda dengan apotek untuk pasien umum. Seringkali obat-obatan yang harganya mahal tidak tersedia di apotek rumah sakit, sehingga pasien harus membelinya di apotek yang tersedia di luar rumah sakit dengan harga normal. Komentar pasien mengenai ketersediaan obat adalah :

H1: "Pelayanan pada Apotek untuk pasien umum lebih cepat, sedangkan pelayanan pada Apotek untuk Gakin (Warga miskin) seringkali antri dan kadangkadang petugasnya istirahat diluar waktu yang telah ditentukan. Dokter memberikan resep obat setiap pagi, dan biasanya obat yang mahal tidak tersedia sehingga harus membelinya ke apotek di luar rumah sakit. Apabila Saya tidak memiliki uang, maka obat tersebut tidak jadi dibeli. Obat yang mahal tersebut seringkali adalah obat antibiotik".

Disamping ketersediaan obat di apotek, kualitas infrastruktur pun diukur melalui kemudahan memperoleh tambahan darah dari bank darah di rumah sakit. Pasien Jamkesmas maupun pasien umum, merasakan pelayanan bank darah yang lebih baik daripada pelayanan apotek. Hal ini kemungkinan karena pasien memiliki saudara yang dapat menjadi donor darah, sehingga tambahan darah mudah didapatkan. Persepsi pasien yang lebih baik tentang ketersediaan bank darah, kemungkinan disebabkan kebutuhan pasien terhadap tambahan darah tidak sesering frekuensi kebutuhan obat-obatan. Disamping itu, harga obat-obatan yang mahal pun menjadikan pasien merasakan ketidakpuasan ketika harus membelinya di luar apotek rumah sakit. Berdasarkan hasil observasi, antrian pada Apotek Jamkesmas lebih panjang, sedangkan pada apotek umum tidak ada antrian yang panjang.
Keluhan pasien terhadap layanan infrastruktur dapat dipahami penyebabnya salah satunya melalui informasi yang diperoleh dari pihak rumah sakit. Berdasarkan informasi yang diperoleh melalui berita di website, kemampuan daerah terbatas dalam menjamin pembiayaan warganya. Adanya beberapa obat-obatan, alat kesehatan, dan pemeriksaan penunjang yang sering diperlukan oleh pasien Jamkesmas, namun tidak terdaftar dalam pedoman pelaksanaan Jamkesmas. Dinas Kesehatan Kabupaten Bandung menetapkan plafon sebesar Rp 3.000.000,-, Kabupaten Bandung Barat Rp 2.500.000,-. per pasien. Tentunya hal ini menjadi kendala dalam pelayanan karena pasien Jamkesmas biasanya memiliki diagnosis severity level (penyakit berat) yang tinggi dengan biaya perawatan yang relatif besar.

\section{Layanan Personal}

Layanan personal merupakan tingkat layanan yang diberikan oleh dokter, seperti keramahan dokter pada pasien dan keluarganya, tingkat keseriusan dokter dalam mendiagnosa penyakit, tingkat kecukupan dari penjelasan hasil tes dan prosedur perawatan oleh dokter, tingkat ketulusan dan keteraturan pengobatan serta perawatan yang diberikan oleh dokter, sejauh mana dokter meluangkan waktu untuk pasien ketika pasien membutuhkan, dan sejauh mana dokter menjawab pertanyaan serta menjelaskan hasil diagnosis dan pengobatan dengan cara yang mudah dipahami oleh pasien. Layanan personal pun mengukur tingkat layanan perawat, seperti tingkat kemampuan perawat dalam memberikan perawatan, tingkat keramahan perawat, tingkat ketepatan dan kecepatan pelayanan yang diberikan oleh perawat, dan tingkat perhatian perawat terhadap kesehatan fisik dan emosi pasien. Persepsi pasien terhadap layanan personal dipengaruhi oleh beberapa faktor, yaitu ketidaktahuan (knowledge); ketidakmauan (attitude); ketidakmampuan (poverty); dan ketidakterjangkauan (geography).

Pasien dengan tingkat pendidikan yang rendah, seringkali tidak menyadari haknya. Hal ini banyak ditemui pada pasien kelas 3. Kalaupun mereka mengetahuinya, mereka tidak mampu menyerap informasi yang diberikan dengan benar. Aspek lain yang mempengaruhi persepsi pasien terhadap layanan personal adalah ketidakmampuan. Akibat dari kemampuan ekonomi yang rendah seringkali 
membuat pasien menuntut kulitas pelayanan yang lebih rendah daripada pasien dengan kemampuan ekonomi yang tinggi. Hal ini sejalan dengan hasil penelitian Setiawan (2007) di mana pada pasien Jamkesmas, seolah-olah tidak ada kesenjangan antara harapan dan kenyataan pelayanan yang dirasakan oleh pasien, padahal pada pasien umum, terdapat gap kualitas yang dirasakan.

Ketidakmauan merupakan sikap yang dimiliki bukan hanya oleh pasien berpendidikan rendah. Pasien dengan pendidikan yang tinggi kadang-kadang tidak mau menggunakan haknya, bahkan menyerahkan segala sesuatunya kepada dokternya (doctors know the best) disebabkan sudah percaya sepenuhnya. Aspek terakhir yang menyebabkan persepsi pasien berbeda-beda adalah ketidakterjangkauan. Beberapa dokter memberikan resep obat melalui media telepon dan dicatat oleh perawat. Tidak adanya komunikasi antara dokter dan pasien secara langsung membuat pasien merasa harus menerima resep obat apa adanya. Apabila dokter bertatap muka langsung dengan pasien, maka pasien akan bertanya bahkan mengungkapkan rasa sakit yang dideritanya dengan lebih baik sehingga tuntutan terhadap kualitas layanan personal menjadi lebih tinggi.

Dokter cukup ramah pada pasien dan keluarganya, tulus, serta serius dalam mendiagnosa penyakit pasien. Keseriusan ini dapat dilihat dari ketelitian selama pemeriksaan, dan keseriusan dalam menjelaskan hasil diagnosa dan bahkan sering meminta pasien atau keluarganya untuk bertanya jika ada hal-hal yang kurang dimengerti. Berdasarkan hasil observasi pada beberapa pasien kelas 3, terlihat bahwa pasien dan keluarganya cenderung pemalu dan pasif. Oleh karena itu, dokter memang dituntut untuk lebih serius dan mendorong pasien untuk lebih terbuka. Namun, keluhan ditemukan mengenai waktu kunjungan dokter. Dokter yang merawat pasien anak, khususnya penderita hydrocephalus, jumlahnya lebih dari satu. Pada kasus penyakit hydrocephalus yang dialami oleh pasien $\mathrm{H} 1$, dokter yang merawatnya adalah dokter anak dan dokter syaraf. Dokter anak selalu siap sedia karena dokter jaga di ruang rawat inap adalah dokter anak. Namun, untuk dokter syaraf, kadang melakukan kunjungan di tengah malam, pernah kunjungan dilakukan pada jam 12 malam dengan alasan sebelumnya harus melakukan operasi.

Hal lain yang dikeluhkan oleh pasien adalah kurangnya komunikasi diantara dokter (other errors) sehingga perkembangan penyakit pasien menjadi tidak jelas. Terjadilah preventive errors adalah kesalahan atau kelambatan dalam mendiagnosa. Keterlambatan ini disebabkan karena masing-masing dokter memberikan diagnosa sendiri, sehingga sering terjadi perbedaan. Masalah akhirnya muncul ketika pasien mengajukan ijin kepulangan, salah satu dokter mengijinkan sedangkan yang lainnya tidak.

Kemampuan perawat menangani perawatan pasien sudah baik, apalagi di ruang bayi. Selain ramah, perawat pun cepat dan tepat dalam memberikan perawatan kepada pasien, terutama untuk perawat shift pagi. Keluhan yang dirasakan oleh pasien kelas 3 baik pasien umum maupun pengguna Jamkesmas adalah kesulitan mendapatkan perawat apabila membutuhkan mereka pada malam hari. Perawat maupun dokter sangat menjaga kebersihan dan kesehatan fisik pasien, bahkan untuk pasien $\mathrm{H} 1$ di ruang perawatan bayi, keluarga maupun pengunjung diharuskan menggunakan baju/rompi rumah sakit dan masker. Namun, untuk perhatian terhadap kestabilan emosional, tidak banyak perawat yang mampu membantu pasien agar merasa tenang.

\section{Proses Perawatan Klinis}

Proses perawatan klinis yaitu tingkat ketepatan dan kecepatan dalam menangani kejadian kritis atau kejadian yang memerlukan pertolongan segera, tingkat sejauhmana perawatan yang diberikan oleh dokter dan perawat setelah operasi, dan sejauhmana kontinuitas informasi yang diberikan mengenai penyakit, termasuk kemungkinan komplikasinya. Menurut persepsi pasien, kejadian yang kritis dan butuh pertolongan segera ditangani baik oleh dokter maupun perawat. Apabila pasien dioperasi, maka setiap hari dokter melakukan observasi. Semua tindakan pasca operasi dilakukan oleh dokter, bukan perawat. Proses perawat klinis dijelaskan lebih lanjut oleh salah seorang penunggu pasien H1, yaitu:

H1: "Dokter bagian bedah syaraf yang langsung memasukkan obat pada kepala anak saya. Dokter juga menjelaskan semua pengobatan yang dilakukan. Suster hanya memeriksa dan melakukan tindakantindakan yang biasa saja, seperti menyuntikan obat ke infus".

\section{Jaminan Keamanan}

Dimensi ini mengukur tingkat perhatian terhadap alergi atau kemungkinan reaksi atas pengobatan 
yang diberikan, tingkat sejauh mana keamanan dan kenyamanan yang diukur melalui tangga yang aman bagi pasien, jalan/gang, elevator dan lift, dan koridor yang disediakan oleh rumah sakit, dan sejauh mana aturan dan prosedur mengenai kebersihan dijalankan oleh dokter dan perawat. Hasil menunjukkan bahwa dokter menjelaskan kemungkinan-kemungkinan efek samping dan reaksi dari pengobatan yang dilakukan. Keluarga pasien diminta untuk terlibat, memonitor, dan melaporkan perkembangan pasien, misalnya apabila pasien muntah atau kejang tanpa sepengetahuan perawat. Setelah pasien pulang pun dokter memberitahu beberapa cara untuk mengukur perkembangan pasien. Misalnya, untuk pasien H1, dokter meminta untuk mengukur kepala bayi H1. Jika terdapat penambahan ukuran kepala sebesar $2 \mathrm{~cm}$ per minggu, berarti terjadi masalah atau kelainan.

Sarana prasarana cukup nyaman dan aman bagi pasien, bahkan di ruang rawat inap bayi, dilengkapi dengan wastafel di setiap sudut ruangan agar dokter dan perawat, serta keluarga pasien dapat mencuci tangan sebelum kunjungan. Sarana dan prasarana sudah cukup memadai baik secara kebersihan maupun jumlahnya. Tidak ditemukan elevator apalagi lift pada ruang inap kelas 3, namun tangga yang ada cukup aman dan luas untuk digunakan. Wastafel ada disetiap sudut ruangan sehingga siapapun yang ingin menemui pasien dapat mencuci tangannya.

\section{Prosedur Masuk}

Dimensi ini mengukur tingkat kemudahan mendapatkan janji (jadwal konsultasi) dengan dokter, lamanya waktu tunggu semenjak pasien masuk ruang rawat inap sampai bertemu dengan dokter, dan sejauh mana waktu yang dibutuhkan untuk menunggu hasil tes-tes dan diagnosis serta layanan laboratorium. Pasien segera mendapatkan ruangan setelah prosedur administratif dan pemeriksaan awal dilakukan. Pelayanan pada pasien Jamkesmas masih diikuti oleh banyak proses yang bersifat prosedural. Hal ini sering dikeluhkan oleh masyarakat. Setelah pasien masuk ruangan, keesokan harinya dokter melakukan kunjungan. Bagi pasien Y1, selanjutnya kunjungan dilakukan 2 kali sehari, sedangkan kunjungan dokter pada pasien H1 dilakukan satu kali per hari. Hasil tes laboratorium dan tes-tes lainnya diperoleh pasien dalam waktu antara $1 / 2$ hari sampai 2 hari. Hasil yang relatif lama ini biasanya disebabkan kerusakan pada perlengkapan komputer.

\section{Analisis Statistik Deskriptif}

Kuesioner yang terkumpul berasal dari responden pada 24 kelas rawat inap, yang berasal dari 4 kelas yang ada pada 6 rumah sakit. Tingkat pendidikan pada responden kelas 1 sebagian besar S1 dan sebagian besar berjenis kelamin perempuan (46\%) dan sebagian besar responden berusia antara 31 sampai 35 tahun. Responden pada kelas 2 sebagian besar berada pada tingkat pendidikan SMA. Pada bagian rawat inap kelas 2 ini, dari 18 responden sebagian besar berjenis kelamin perempuan $(46 \%)$ dan sebagian besar responden berusia antara 31 sampai 35 tahun.

Responden pada kelas 3 sebagian besar tingkat pendidikannya pada jenjang SMA. Pada bagian rawat inap kelas 3 ini, sebagian besar berjenis kelamin perempuan $(42 \%)$ dan berusia antara 26 sampai 30 tahun. Responden pada kelas VIP, tingkat pendidikannya sebagian besar antara jenjang SMA dan S1 dan sebagian besar berjenis kelamin perempuan (46\%) serta berusia antara 31 sampai 35 tahun. Secara umum hanya sedikit perbedaan karakteristik responden pada kelas 1, 2, 3, dan VIP. Perbedaan tersebut dapat dilihat pada Tabel 3.

Tabel 3. Karakteristik Responden

\begin{tabular}{lllc}
\hline Kelas & Tingkat Pendidikan & Jenis Kelamin & Usia \\
\hline 1 & S1 & perempuan & 31 s.d 35 \\
2 & SMA & perempuan & 31 s.d 35 \\
3 & SMA & perempuan & 26 s.d 30 \\
VIP & SMA dan S1 & perempuan & 31 s.d 35 \\
\hline
\end{tabular}

Responden dengan karakteristik tersebut telah memberikan tanggapan atas pertanyaan mengenai kualitas layanan rumah sakit. Berdasarkan tanggapan tersebut, maka kondisi masing-masing dimensi kualitas layanan rumah sakit yang diteliti, dapat dilihat pada Tabel 4.

Berdasarkan Tabel 4. dapat dilihat bahwa secara umum kualitas layanan sudah cukup baik walaupun terdapat persepsi yang kurang puas terhadap waktu yang disediakan oleh dokter yang tidak selalu tersedia (P8), upaya rumah sakit belum secara kontinyu memberikan informasi mengenai penyakit, termasuk kemungkinan komplikasinya (P15), dan kurangnya upaya rumah sakit untuk melatih pasien dan memberi penjelasan pada keluarganya tentang pengelolaan rasa sakit dan keluhan (P29). 
Tabel 4. Hasil Statistik Deskriptif Kualitas Layanan

\begin{tabular}{|c|c|c|c|c|c|c|c|c|c|c|}
\hline \multicolumn{11}{|c|}{ Kualitas Layanan } \\
\hline & \multirow{2}{*}{ Variabel dan Indikator } & \multirow{2}{*}{ Min } & \multirow{2}{*}{ Max } & \multirow{2}{*}{ Mean } & \multirow{2}{*}{ Std Dev } & \multirow{2}{*}{ Modus - } & \multicolumn{4}{|c|}{ Skala } \\
\hline & & & & & & & 1 & 2 & 3 & 4 \\
\hline $\mathrm{P} 1$ & $\begin{array}{l}\text { Obat-obatan yang dibutuhkan oleh pasien, mudah didapatkan di apotik } \\
\text { rumah sakit ini. }\end{array}$ & 3 & 4 & 1.88 & 0.816 & 3 & 0 & 0 & 13 & 11 \\
\hline P2 & $\begin{array}{l}\text { Apabila pasien membutuhkan tambahan darah, maka dengan mudah } \\
\text { didapatkan di bank darah milik rumah sakit ini. }\end{array}$ & 2 & 4 & 2.55 & 0.792 & 3 & 0 & 4 & 19 & 1 \\
\hline P3 & Dokter dan perawat sangat ramah kepada pasien dan keluarga. & 2 & 4 & 3.06 & 0.874 & 4 & 0 & 1 & 12 & 11 \\
\hline P4 & $\begin{array}{l}\text { Dokter sangat serius (bersungguh-sungguh) dalam mendiagnosa penyakit } \\
\text { pasien. }\end{array}$ & 2 & 4 & 3.06 & 0.863 & 3 & 0 & 1 & 17 & 6 \\
\hline P5 & Perawat mampu memberikan perawatan sesuai dengan kebutuhan pasien. & 2 & 4 & 3.06 & 0.873 & 3 & 0 & 1 & 16 & 7 \\
\hline P6 & $\begin{array}{l}\text { Dokter memberikan penjelasan yang bisa dipahami mengenai hasil tes } \\
\text { dan prosedur pengobatan yang dilakukannya. }\end{array}$ & 2 & 4 & 2.55 & 0.904 & 3 & 0 & 4 & 12 & 8 \\
\hline P7 & $\begin{array}{l}\text { Dokter dengan tulus dan teratur dalam memberikan pengobatan } \\
\text { dan perawatan kepada pasien. }\end{array}$ & 2 & 4 & 2.55 & 0.911 & 2 & 0 & 4 & 12 & 8 \\
\hline P8 & Dokter selalu meluangkan waktu setiap saat pasien membutuhkan. & 2 & 4 & 2.06 & 0.919 & 2 & 0 & 10 & 10 & 4 \\
\hline P9 & $\begin{array}{l}\text { Dokter menjawab pertanyaan dan menjelaskan hasil diagnosis dan } \\
\text { pengobatan dengan cara yang mudah dipahami oleh pasien atau keluarganya. }\end{array}$ & 2 & 4 & 2.4 & 0.914 & 2 & 0 & 5 & 11 & 8 \\
\hline P10 & Perawat sangat ramah kepada pasien dan keluarganya. & 2 & 4 & 3.06 & 0.874 & 4 & 0 & 2 & 12 & 10 \\
\hline P11 & Perawat memberikan pelayanan dengan tepat dan cepat. & 2 & 4 & 2.4 & 0.919 & 2 & 0 & 6 & 11 & 7 \\
\hline P12 & Perawat sangat memperhatikan kesehatan fisik dan emosi pasien. & 2 & 4 & 2.55 & 0.893 & 2 & 0 & 5 & 15 & 4 \\
\hline P13 & $\begin{array}{l}\text { Pada saat pasien kritis atau memerlukan pertolongan segera, } \\
\text { maka ditangani dengan tepat dan cepat. }\end{array}$ & 2 & 4 & 2.55 & 0.905 & 2 & 0 & 4 & 15 & 5 \\
\hline P14 & $\begin{array}{l}\text { Pada pasien yang telah dioperasi, maka dokter dan perawat memberikan } \\
\text { perawatan yang intensif. }\end{array}$ & 2 & 3 & 3.06 & 0.486 & 3 & 0 & 1 & 23 & 0 \\
\hline P15 & $\begin{array}{l}\text { Rumah sakit secara kontinyu memberikan informasi mengenai penyakit, } \\
\text { termasuk kemungkinan komplikasinya. }\end{array}$ & 2 & 4 & 2.27 & 0.884 & 2 & 0 & 7 & 15 & 2 \\
\hline P16 & $\begin{array}{l}\text { Rumah sakit memberikan perhatian terhadap kemungkinan alergi atau } \\
\text { kemungkinan reaksi atas pengobatan yang diberikan kepada pasien. }\end{array}$ & 2 & 4 & 3.06 & 0.745 & 3 & 0 & 1 & 21 & 2 \\
\hline P17 & Rumah sakit menyediakan tangga yang aman bagi pasien. & 3 & 4 & 1.35 & 0.718 & 1 & 0 & 0 & 20 & 4 \\
\hline P18 & $\begin{array}{l}\text { Rumah sakit menyediakan ruangan dan kamar mandi yang aman } \\
\text { dan nyaman bagi pasien. }\end{array}$ & 2 & 4 & 2.75 & 0.9 & 2 & 0 & 3 & 13 & 8 \\
\hline P19 & $\begin{array}{l}\text { Rumah sakit menyediakan jalan yang melandai dan aman untuk kursi roda } \\
\text { atau usungan pasien. }\end{array}$ & 3 & 4 & 1.42 & 0.753 & 1 & 0 & 0 & 19 & 5 \\
\hline P20 & Rumah sakit menyediakan elevator dan lift yang aman dan nyaman bagi pasien. & 3 & 4 & 1.5 & 0.778 & 1 & 0 & 0 & 18 & 6 \\
\hline P21 & Rumah sakit menyediakan koridor yang lapang. & 2 & 4 & 2.75 & 0.884 & 3 & 0 & 3 & 16 & 5 \\
\hline P22 & $\begin{array}{l}\text { Dokter dan perawat selalu menjalankan aturan dan prosedur mengenai } \\
\text { kebersihan (misalnya mencuci tangan, menggunakan sarung tangan). }\end{array}$ & 3 & 4 & 1.5 & 0.778 & 1 & 0 & 0 & 18 & 6 \\
\hline P23 & $\begin{array}{l}\text { Pasien mudah mendapatkan janji (jadwal konsultasi) dengan dokter yang } \\
\text { dibutuhkannya. }\end{array}$ & 1 & 4 & 3.06 & 0.91 & 3 & 1 & 5 & 15 & 3 \\
\hline P24 & $\begin{array}{l}\text { Setelah pasien masuk ke dalam ruang rawat inap, maka dengan segera } \\
\text { dokter yang menanganinya melakukan kunjungan. }\end{array}$ & 2 & 4 & 2.4 & 0.908 & 2 & 0 & 6 & 14 & 4 \\
\hline P25 & $\begin{array}{l}\text { Pasien dan keluarganya bisa segera mengetahui dengan cepat hasil scan } \\
\text { dan hasil pemeriksaan laboratorium lainnya. }\end{array}$ & 2 & 4 & 3.06 & 0.825 & 3 & 0 & 2 & 18 & 4 \\
\hline P26 & Pasien diberikan penjelasan dan rencana pengobatannya serta risiko-risikonya. & 2 & 4 & 2.4 & 0.908 & 2 & 0 & 5 & 14 & 5 \\
\hline P27 & Efek pengobatan terhadap pasien terus menerus dimonitor. & 2 & 4 & 2.4 & 0.908 & 2 & 0 & 5 & 15 & 4 \\
\hline P28 & $\begin{array}{l}\text { Perawat dan paramedis memberi informasi tentang rencana pelayanan } \\
\text { dan mengikutksertakan pasien dan keluarganya dalam menentukan } \\
\text { pelaksanaannya. }\end{array}$ & 2 & 4 & 2.55 & 0.893 & 2 & 0 & 4 & 16 & 4 \\
\hline P29 & $\begin{array}{l}\text { Rumah sakit melatih pasien dan memberi penjelasan pada keluarganya } \\
\text { tentang pengelolaan rasa sakit dan keluhan. }\end{array}$ & 2 & 4 & 2.06 & 0.919 & 2 & 0 & 11 & 9 & 4 \\
\hline P30 & Makanan dan nutrisi yang sesuai untuk pasien, diberikan secara teratur. & 2 & 4 & 2.75 & 0.884 & 3 & 0 & 3 & 16 & 5 \\
\hline
\end{tabular}




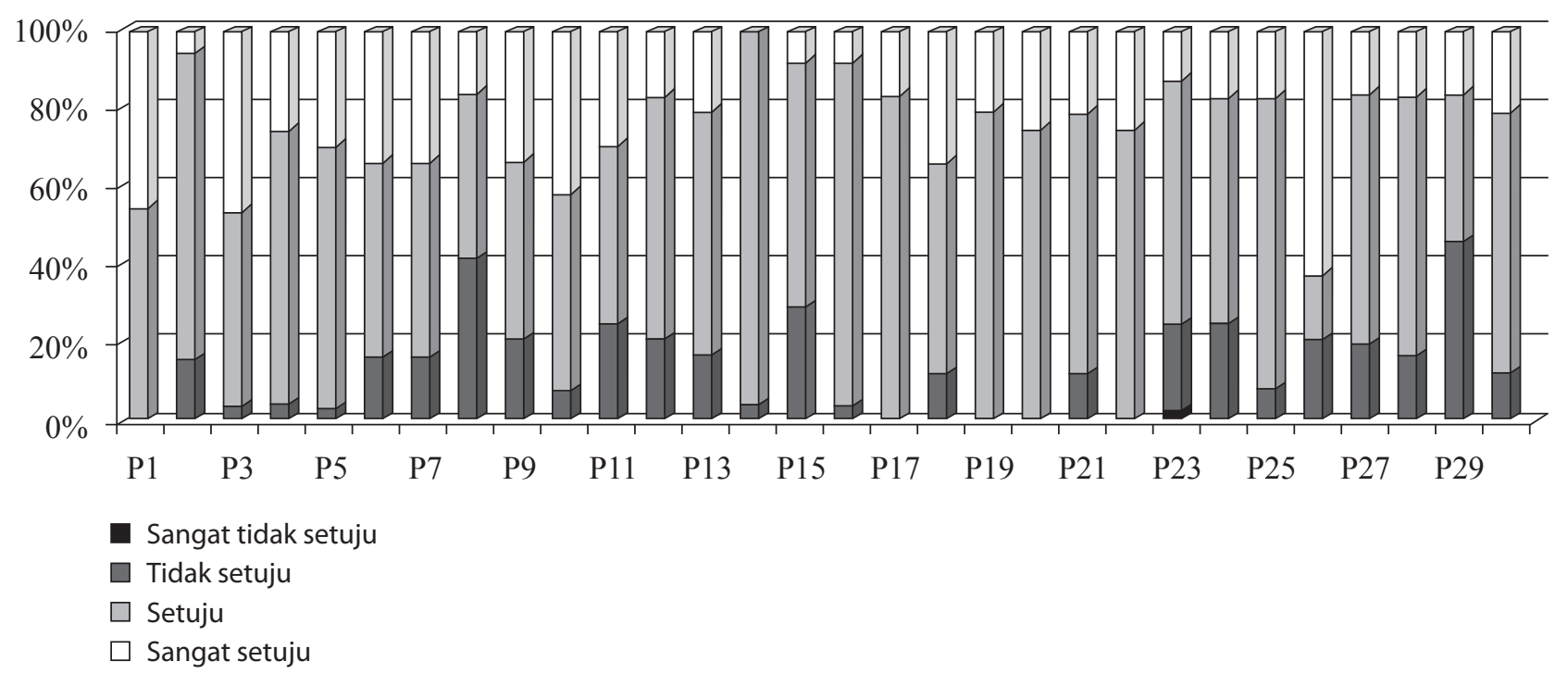

Gambar 1. Diagram Tanggapan Responden

Berdasarkan Gambar 1. dapat dilihat bahwa kualitas layanan pada 6 rumah sakit di Bandung menunjukkan masih adanya dimensi yang relatif kurang memuaskan dibandingkan keseluruhan dimensi yaitu pada dimensi ketepatan perawatan. Dilain pihak, diantara seluruh dimensi kualitas layanan, maka dimensi jaminan keamanan merupakan dimensi yang paling memuaskan.

\section{KESIMPULAN}

Penelitian ini memberikan kontribusi dengan memberikan gambaran mengenai kualitas layanan rumah sakit di bagian rawat inap. Hasil penelitian menunjukkan bahwa kualitas layanan rumah sakit di Bandung relatif sudah cukup baik terutama dalam menjamin keamanan pada pasien. Beberapa ketidakpuasan terjadi, yaitu terhadap pelayanan dokter. Waktu yang disediakan oleh dokter tidak selalu sesuai dengan kebutuhan pasien. keluhan lain yaitu rumah sakit belum secara kontinyu memberikan informasi mengenai penyakit, termasuk kemungkinan komplikasinya kepada pasien dan rumah sakit belum benar-benar berupaya untuk melatih pasien dan memberi penjelasan pada keluarganya tentang pengelolaan rasa sakit dan keluhan.

Berdasarkan hasil penelitian permasalahan yang banyak dikeluhkan oleh pasien yaitu mengenai layanan personal yang diberikan oleh dokter. Oleh karena itu perlu penelitian tentang motivasi kerja dokter, dan kompetensi dokter sehingga dapat diketahui faktor yang dominan dalam mempengaruhi layanan personal dokter. Perlu juga dilakukan penelitian tentang kecocokan antara persepsi organisasi dan pegawai dalam upaya memperantarai pengaruh motivasi dan kompetensi dokter terhadap kualitas layanan rumah sakit.

Komunikasi antara rumah sakit dengan pasien perlu diperbaiki karena masih adanya keluhan mengenai belum jelasnya informasi yang diberikan pada pasien mengenai penyakit dan rencana pengobatan, serta berbagai risiko yang dihadapi selama dalam perawatan. Penggunaan sistem informasi yang tepat dalam rangka transfer knowledge mungkin dapat digunakan sebagai media komunikasi secara tidak langsung dengan pasien mengenai penyakit dan perawatan yang direncanakan.

Penelitian dilakukan pada sampel yang terbatas sehingga tidak dapat dilakukan generalisasi. Oleh karena itu, penelitian selanjutnya diharapkan mampu dilakukan pada ukuran populasi atau sampel yang lebih besar. Hasil penelitian dapat diperbaiki pula dengan menambahkan dokter dan perawat, serta pasien kelas 1 dan VIP sebagai responden dalam wawancara, sehingga dapat diperoleh gambaran mengenai kualitas layanan rumah sakit yang lebih nyata. 


\section{DAFTAR PUSTAKA}

Andaleeb, S. S. 2000. Public and Private Hospitals In Bangladesh: Service Quality and Predictors Of Hospital Choice. Health Policy and Planning, 15(1): 95-102.

Choi, J. H. 2006. The Relationship Among Transformational Leadership, Organizational Outcomes, and Service Quality In the Five Major NCAA Conferences, A Record of Study, Submitted to the Office of Graduate Studies of Texas A\&M University, In Partial Fulfillment of The Requirements for the Degree of Doctor of Education.

Duggirala, M., Rajendran, C., Anantharaman, R. N. 2008. Patient-Perceived Dimensions of Total Quality Service In Healthcare. Benchmarking: An International Journal, 15(5): 560-583.

Eleid, G. R. 2009. Exploring the Perceptions of Healthcare Quality Among Lebanese Stakeholders, A Dissertation Presented In Partial Fulfillment of the Requirements for the Degree Doctor of Health Administration, University of Phoenix, August 2009, UMI Dissertation.

Jabnoun, N., and Rasasi, A. J. A. L. 2005. Transformational Leadership and Service Quality In UAE Hospitals. Managing Service Quality, 15: 70-81.

Jonirasmanto. 2009. Mutu Pelayanan Kesehatan: Ambivalensi Antara Kewajiban dan Keinginan (Antara Penyelenggara dan Pemilik). Hal Mutu Pelayanan Rumah Sakit, 05.11.

Karassavidou, E., Glaveli, N., and Papadopoulos, C. T. 2009. Quality In NHS Hospitals: No One Knows Better Than Patients. Measuring Business Excellence, 13(1): 34-46.

Keogh, Bruce. 2013. Review Into the Quality of Care and Treatment Provided by 14 Hospital Trusts In England: Overview Report.

Ko, Y. J., Kim, Y. K., Kim, M. K., and Lee, J. H. 2010. The role of Involvement and Identification on Event Quality Perceptions and Satisfaction - A Case of US Taekwondo Open, Asia Pacific Journal of Marketing and Logistics, 22(1): 25-39.

Kotler, P. and Keller, K. L. 2006 Marketing Management, Pearson Education.

Manjunath, U., Metri, B. A., and Ramachandran, S. 2007. Quality Management In A Healthcare Organisation: A Case of South Indian Hospital. The TQM Magazine, 19(2): 129-139.
Mukherjee, A. and Malhotra, N. 2006. Does Role Clarity Explain Employee-Perceived Service Quality?, A Study Of Antecedents And Consequences In Call Centres. International Journal Of Service Industry Management, 17(5): 444-473.

Nadiri, H., and Tümer, M. 2009. Retail Service Quality And Behavioural Intentions: An Empirical Application of the Retail Service Quality Scale In Northern Cyprus. E+M Ekonomie A Management, 2: 127 .

Parasuraman, A., Zeithaml, V. A., and Berry, L. L. 1994. Alternative Scales For Measuring Service Quality: A Comparative Assessment Based On Psychometric And Diagnostic Criteria. Journal Of Retailing, 70(3): 201-230.

Paccioni, A, Sicotte, C., and Champagne, F. 2008. Accreditation: a Cultural Control Strategy. International Journal of Health Care Quality Assurance, 21(2): 146-158.

Raja, M. P. N., Deshmukh, S. G., and Wadhwa, S. 2007. Quality Award Dimensions: A Strategic Instrument For Measuring Health Service Quality, International Journal of Health Care Quality Assurance, 20(5): 363-378.

Saurina, C. and Coenders, G. 2002. Redicting Overall Service Quality-A Structural Equation Modelling Approach, Developments In Social Science Methodology. Metodološki Zvezki, 18.

Suh, Y. I. and Pedersen, P. M. 2010. Participants Service Quality Perceptions of Fantasy Sports Websites: The Relationship Between Service Quality, Customer Satisfaction, Attitude, and Actual Usage. Sport Marketing Quarterly, 19: 78-87.

Supratman, D. dan Prasetyo, E. 2010. Bisnis Orang Sakit. Yogyakarta: Resist Book.

Theodorakioglou, Y. D. and Tsiotras, G. D. 2000. The Need For The Introduction of Quality Management Into Greek Health Care. Total Quality Management, 11(8): 1153.

Yin, R. K. 1994. Case Study Research: Design and Methods, London: Sage Publications.

Yusup, A. 2007. Perbandingan Persepsi Kualitas Layanan Balai Pengobatan Menurut Petugas dan Pasien pada Penerapan Kebijakan Pengobatan Gratis di Puskesmas Kabupaten Indramayu, Tesis, Pascasarjana, Unpad.

Zarei, Asghar et al. 2012. Service Quality of Private Hospitals: The Iranian Patients' Perspective. BMC Health Services Research, 12: 31. 